\title{
CHARACTERIZATION OF THICK FILM CAPICITORS
}

\author{
Y. LEROY, M. DESCAMPS and M. VERNET \\ Département Genie Electrique, I.U.T. de Lille, Sac Postal n 59650, Villeneuve D’Ascq, France
}

(Received March 10, 1977)

\begin{abstract}
Teaching activities of the "Institut Universitaire de Technologie de Lille" (France) were previously reported.
The present paper reports measurement results obtained by students during their last training period for about a hundred capacitors made with commercial dielectrics (EMCA CDP 400, EMCA CDP 2000, and ESL K 1000).

We examine the following points: reproducibility of capacitors during fabrication, correlation between electrical parameters of components and firing conditions, measurements of capacitance and loss factor between $10 \mathrm{kHz}$ and $20 \mathrm{MHz}$ for temperatures ranging from $20^{\circ} \mathrm{C}$ to $100^{\circ} \mathrm{C}$.
\end{abstract}

\section{FOREWORD}

Teaching activities of the Institut Universitaire de Technologie de Lille (Département "Génie Electrique") in the thick film field have previously been reported. ${ }^{1-3}$ The principle of operation and fabrication of hybrid circuits is taught to the students as a part of their training in electronics. Moreover, every year several students spend two months in our thick film laboratory for their training period which take place at the end of the two year course. In this paper the results obtained in 1976 are reported.

We studied the electric characterization of thick film capacitors for the following reasons. Discussions with thick film specialists lead to the conclusion that study of reproducibility of capacitors during fabrication and correlation between electrical parameters of components and firing conditions is required. Effects produced by firing conditions have to be known either to specify the temperature and time margin authorized for getting the same permittivity, or to adjust this parameter to a desired value. Values of capacitances and of their loss factor versus frequency and temperature may also be very useful. Specialized papers provide a good deal of data concerning complex permittivity of glasses, titanates and other dielectrics ${ }^{4}$ but unfortunately this information is useless for the designer who is concerned with pastes whose composition is generally unknown to him. On the other hand, the growing use of screened capacitors necessitates the knowledge of a greater number of parameters. However it is obvious that each ink manufacturer cannot supply all the desired parameters for all the possible applications. Specific information can be investigated through particular studies for example the one presented here.

\section{PRESENTATION OF STUDIED COMPONENTS}

Results and conclusion reported in this paper come from an experimental study carried out on about a hundred capacitors made with commercial dielectric pastes screened with 200 mesh grids. These capacitors were fired in a four zone Piezo-ceram oven which allows systematic experiments versus time and firing temperature. Several screen printing types of operation were considered. The materials used were EMCA CDP 400, EMCA CDP 2000, Electro Science K 1000 and Cermalloy 9100 which are mean and high permittivity materials and a cross over dielectric. The conductor paste used was EMCA 4249.

We successively examined the problem of reproducibility in capacitor fabrication, the results concerning capacitance and loss factor measurements versus manufacturing parameters, frequency and temperature.

\section{REPRODUCTIVITY OF FABRICATION}

We considered a screened, flat, rectangular capacitor whose thickness, length and width are $e, a$ and $b$, respectively.

The dispersion on capacitances $\Delta c$ can be related to the variations of geometrical parameters $\Delta e, \Delta a$ 
and $\Delta b$. It can be estimated by

$$
\frac{\Delta c}{c}=\frac{\Delta e}{e}+\frac{a+b}{a b} \Delta a
$$

with $\Delta a \cong \Delta b$.

The thickness $e$ was measured with a stylus profilometer. For one printing, the value of $e$ was near 15 microns but two printing operations were generally preferred, which is recommended by the ink manufacturers. In this case, $e$ was near 30 microns with $\Delta e$ $\cong 2$ microns on a series of 20 capacitors. We also measured $\Delta a \cong 50$ microns. In these conditions for $0,63 \mathrm{~mm}^{2}$ area capacitors ( $a=0,9 \mathrm{~mm} ; b=0,7 \mathrm{~mm}$ ) we estimated:

$$
\frac{\Delta c}{c} \cong 20 \%
$$

in fact dispersion on measured capacitances gave generally

$$
\frac{\Delta c}{c}<15 \%
$$

A smaller error can be predicted when the area of the capacitor increases. For instance, for a $0.5 \mathrm{~cm}^{2}$ area, we can obtain

$$
\frac{\Delta c}{c}<7 \%
$$

\section{DIELECTRIC PROPERTIES}

Measurement of capacitance and loss factor was carried out on $0.63 \mathrm{~mm}^{2}$ area capacitors, using a low frequency bridge and a $\mathrm{Q}$ meter. In this work, we operated in the frequency range $10 \mathrm{kHz}$ to $20 \mathrm{MHz}$.

Dielectric pastes EMCA CDP 400 and CDP 2000 were fired at $850^{\circ}, 900^{\circ}$ and $950^{\circ}$ with 10 minute firing times. The bottom electrode was fired first and then the dielectric and top electrode were fired together. In several cases, the three films were fired separately but no significantly different results were observed. Some typical examples concerning capacitance and loss factor at room temperature are presented in Figures 1 and 2 (CDP 2000 for $850^{\circ}$,

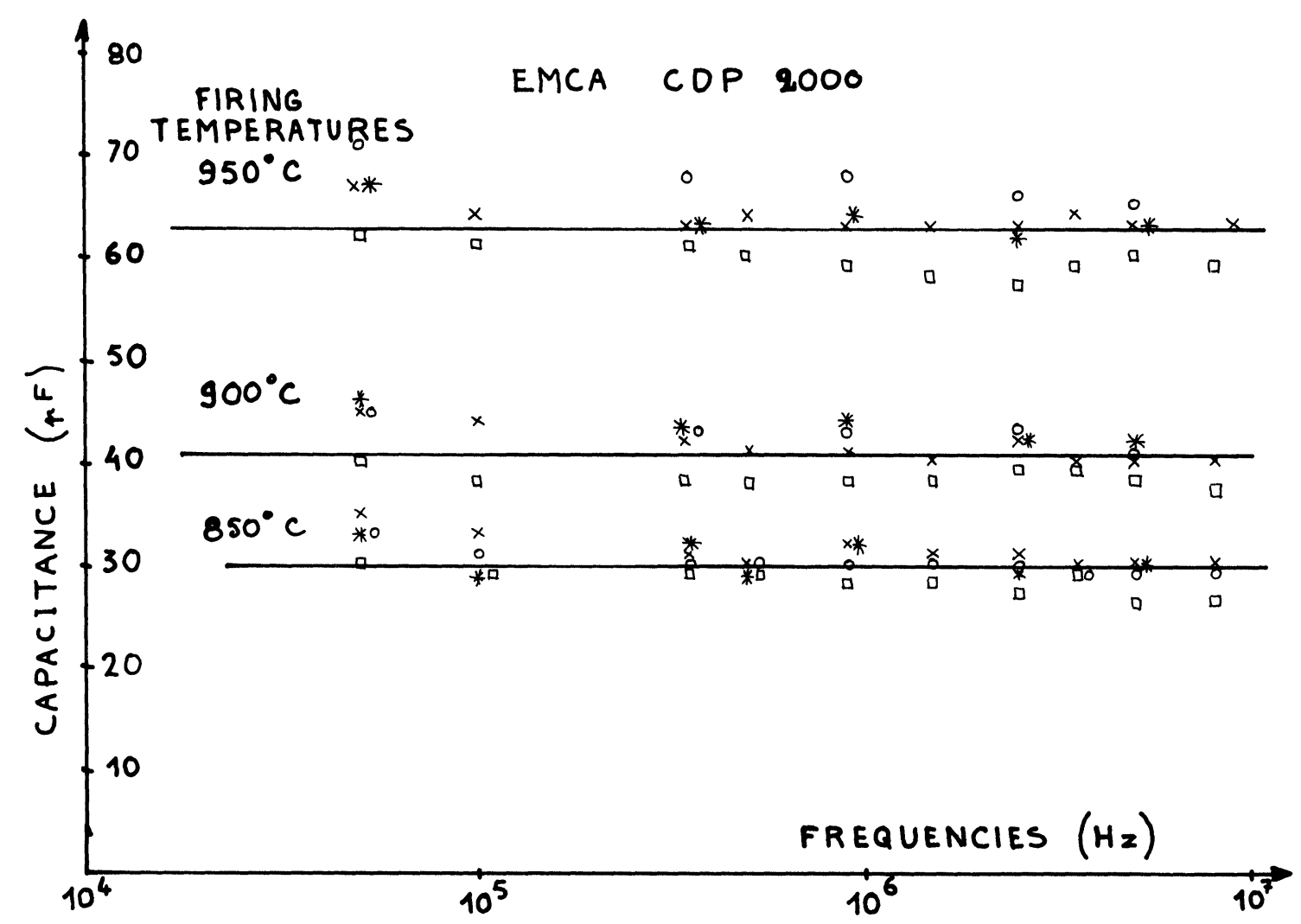

FIGURE 1 Capacitance vs. frequency for various firing temperatures. EMCA CDP 2000. 


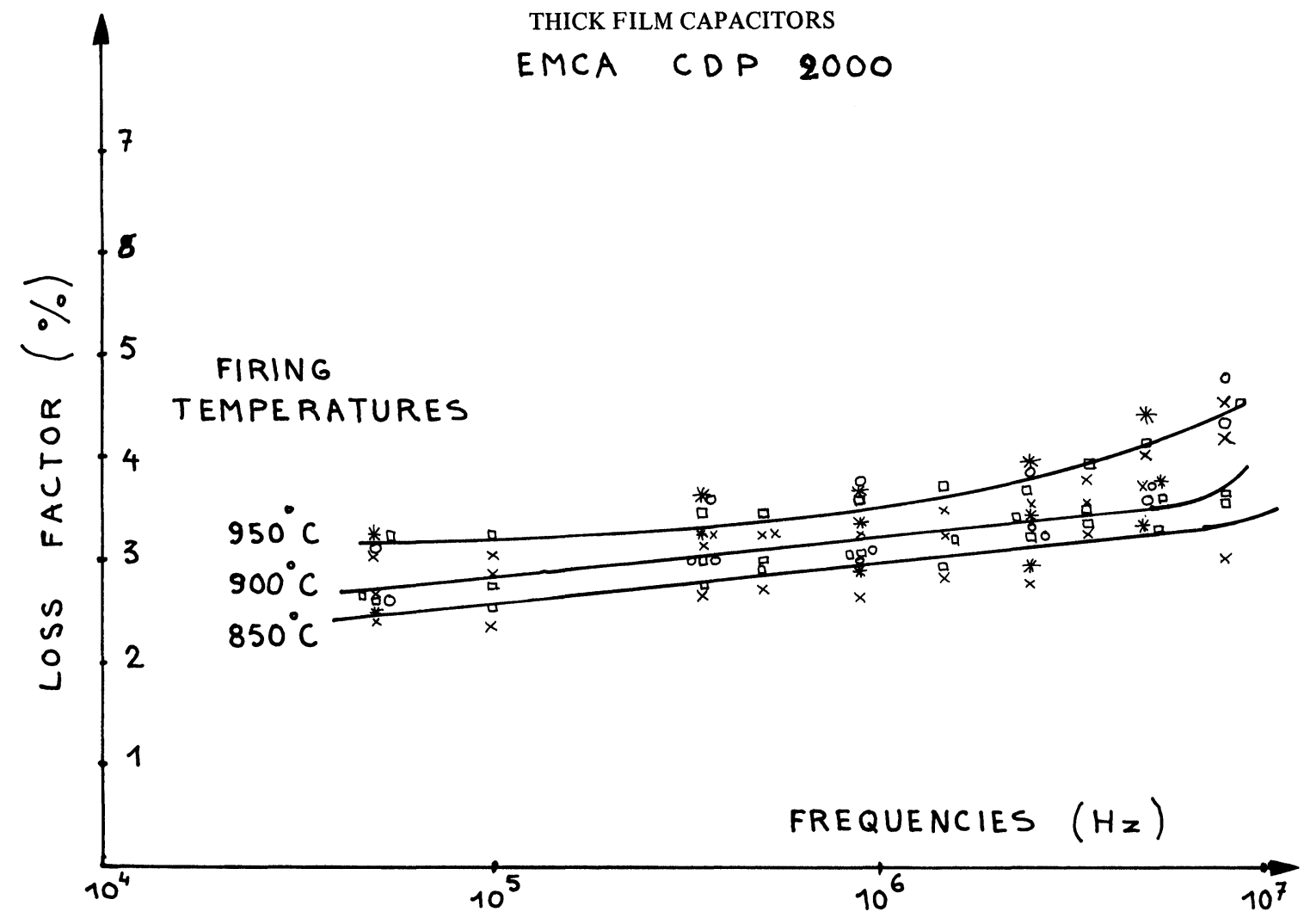

FIGURE 2 Loss factor vs. frequency for various firing temperatures. EMCA CDP 2000.

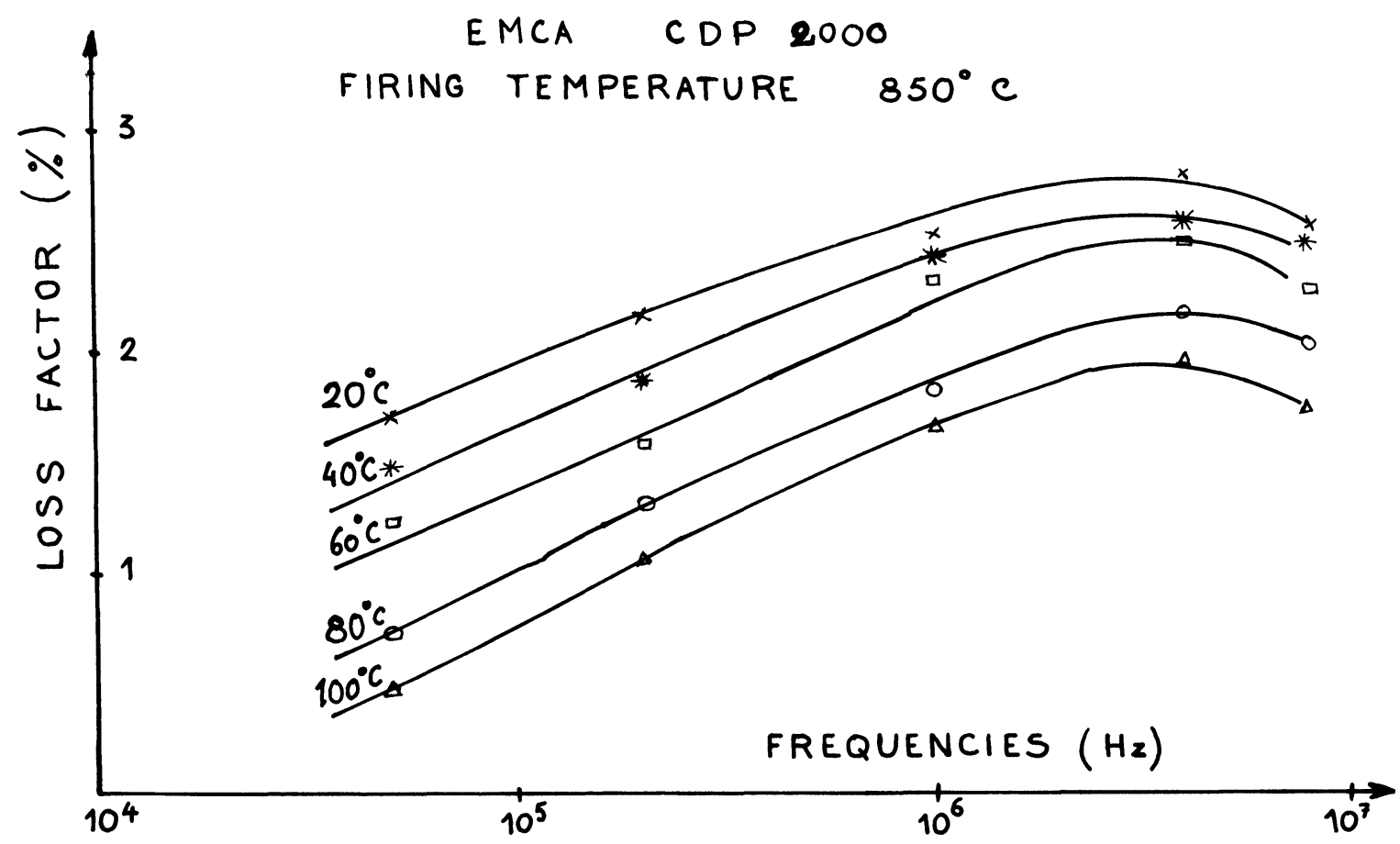

FIGURE 3 Loss factor vs. frequency for $850^{\circ} \mathrm{C}$ firing temperature for various substrate temperatures. EMCA CDP 2000. 


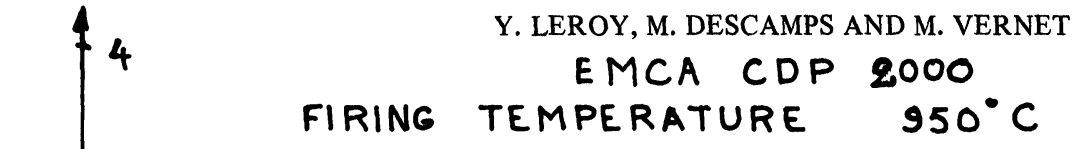

3

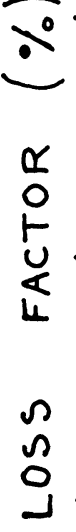

1

10

$100^{\circ} \mathrm{C}$ 


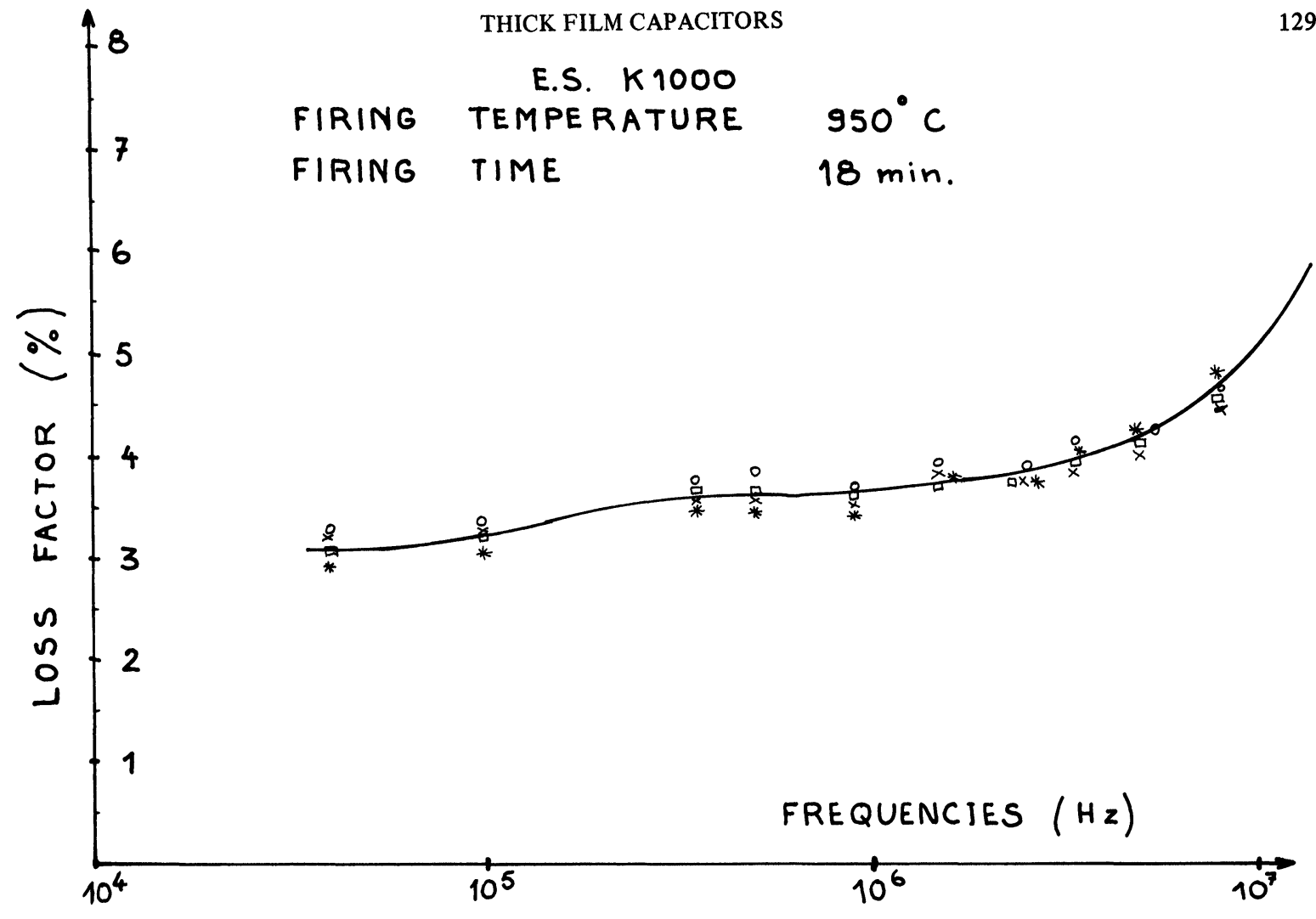

FIGURE 6 Loss factor vs. frequency for $950^{\circ} \mathrm{C}$ firing temperature for several samples. E.S. K1000.

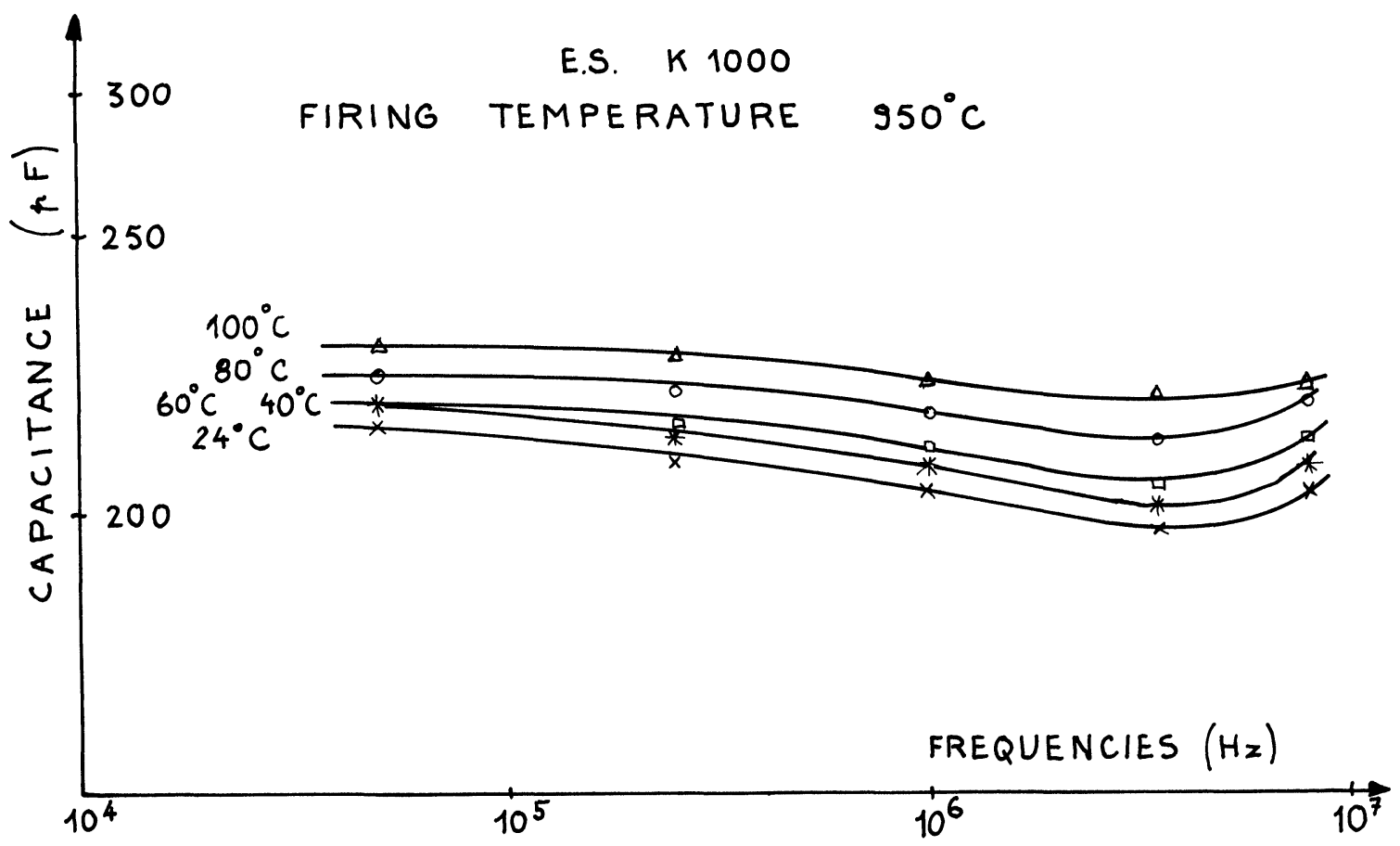

FIGURE 7 Capacitance vs. frequency for $950^{\circ} \mathrm{C}$ firing temperature for various substrate temperatures. E.S. K1000. 


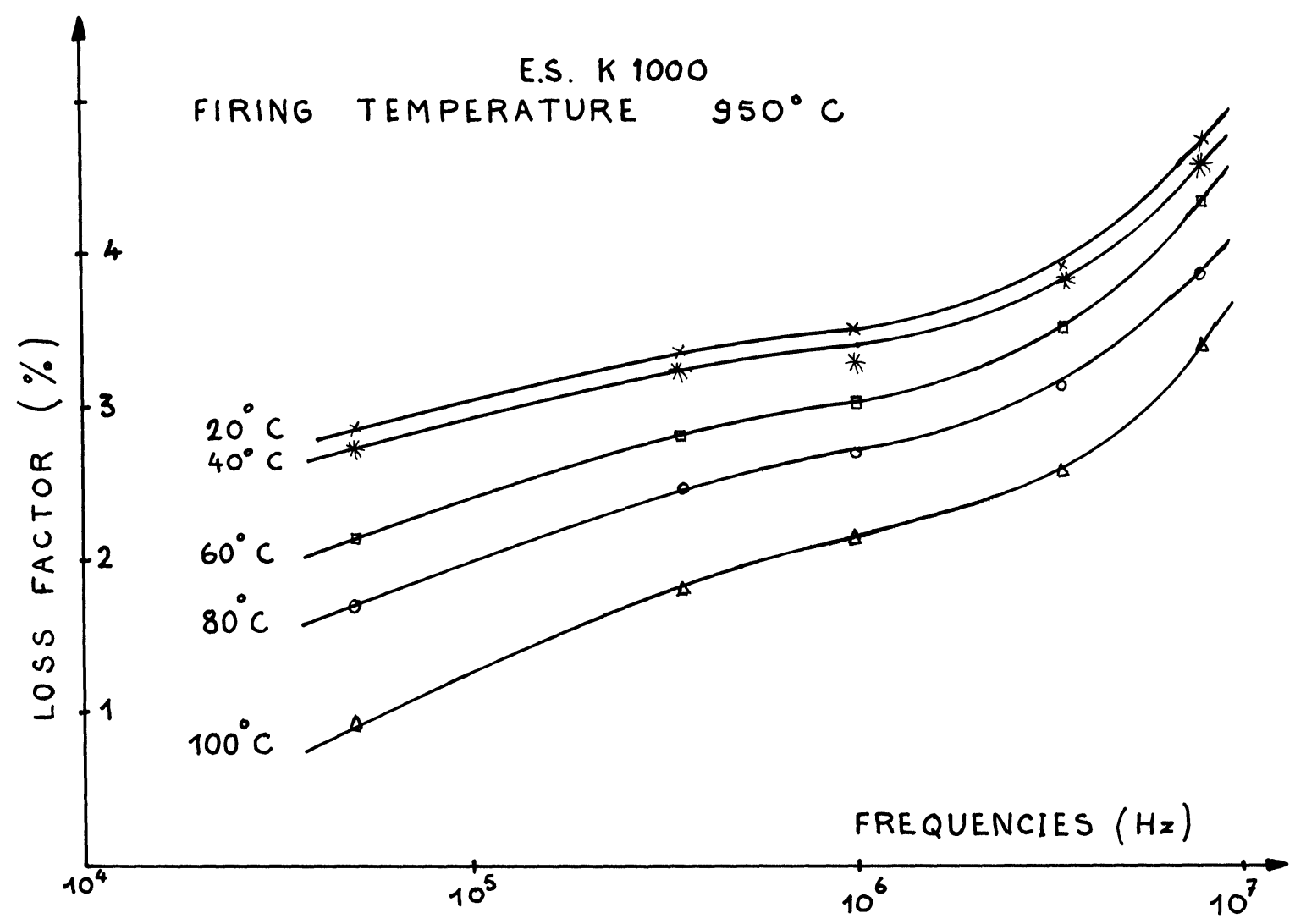

FIGURE 8 Loss factor vs. frequency for $950^{\circ} \mathrm{C}$ firing temperature for various substrate temperatures. E.S. K1000.

$900^{\circ}$ and $950^{\circ}$ firing temperature). For the same component, the capacitance was quite constant for the frequency range considered. For the same firing temperature, the two pastes yield practically the same capacitance. Their mean values are

$$
\begin{aligned}
& 32 \pm 2 \mathrm{pF} \text { for } 850^{\circ} \mathrm{C} \\
& 36 \pm 6 \mathrm{pF} \text { for } 900^{\circ} \mathrm{C} \\
& 64 \pm 4 \mathrm{pF} \text { for } 950^{\circ} \mathrm{C}
\end{aligned}
$$

For one dielectric printing (firing temperature $850^{\circ} \mathrm{C}$ ), we obtained $C=50 \pm 3 \mathrm{pF}$, but in several cases, a short circuit occurred. No significant variation of $C$ was observed when the substrate was heated (from room temperature to $100^{\circ} \mathrm{C}$ ) but the loss-factor decreased (Figures 3 and 4).

Dielectric paste Electro-Science K 1000 was fired at $950^{\circ} \mathrm{C}$ and $975^{\circ} \mathrm{C}$ with 8 minute, 13 minute and 18 minute firing times. At $50 \mathrm{kHz}$, the mean capacitance was $C=213 \pm 25 \mathrm{pF}$ ( 25 components). In the present conditions, no influence of firing parameters was observed. Examples of variation of $C$ and $\tan \delta$ for several samples are shown in Figure 5 and 6. For this high permittivity dielectric, a slight increase of permittivity and a decrease of loss factor were noticed when the substrate was heated from room temperature to $100^{\circ} \mathrm{C}$ (Figures 7 and 8).

Dielectric paste Cermannoy 9100 was previously studied. ${ }^{3}$ Capacitance was smaller than $2 \mathrm{pF} / \mathrm{mm}^{2}$ and loss factor could reach 0.1 .

\section{CONCLUSION}

Choice of the dielectric paste depends on the application. For instance capacitor fabrication needs low loss materials with high permittivity which has to be constant versus frequency and temperature. The cross over demands the lowest permittivity material; loss factor value is not so important in this case as in the previous example. 


\section{ACKNOWLEDGEMENTS}

The authors wish to thank here several Frensh thick film specialists for fruitful discussions about technology, and particularly M. Dreyfus-Alain (Chairman ISHM France),

M. Kersuzan (T.R.T.), M. Monneraye (L.E.P.), M. Gaulard (E.S.L.) and M. Lambert (Comatel).

\section{REFERENCES}

1. Y. Leroy, and M. Descamps, Electronique et Microélectronique Industrielle, 15 mai 1974.
2. Y. Leroy, M. Descamps and M. Vernet, Conférence on Hybrid Microelectronics, Loughborough (G.-B.), septembre 1975.

3. Y. Leroy, M. Descamps and M. Vernet, Colloque International sur les Circuits Hybrides, Paris, avril 1976.

4. C. A. Harper, Handbook of Thick Film Hybrid Microelectronic, Chapter 7. 

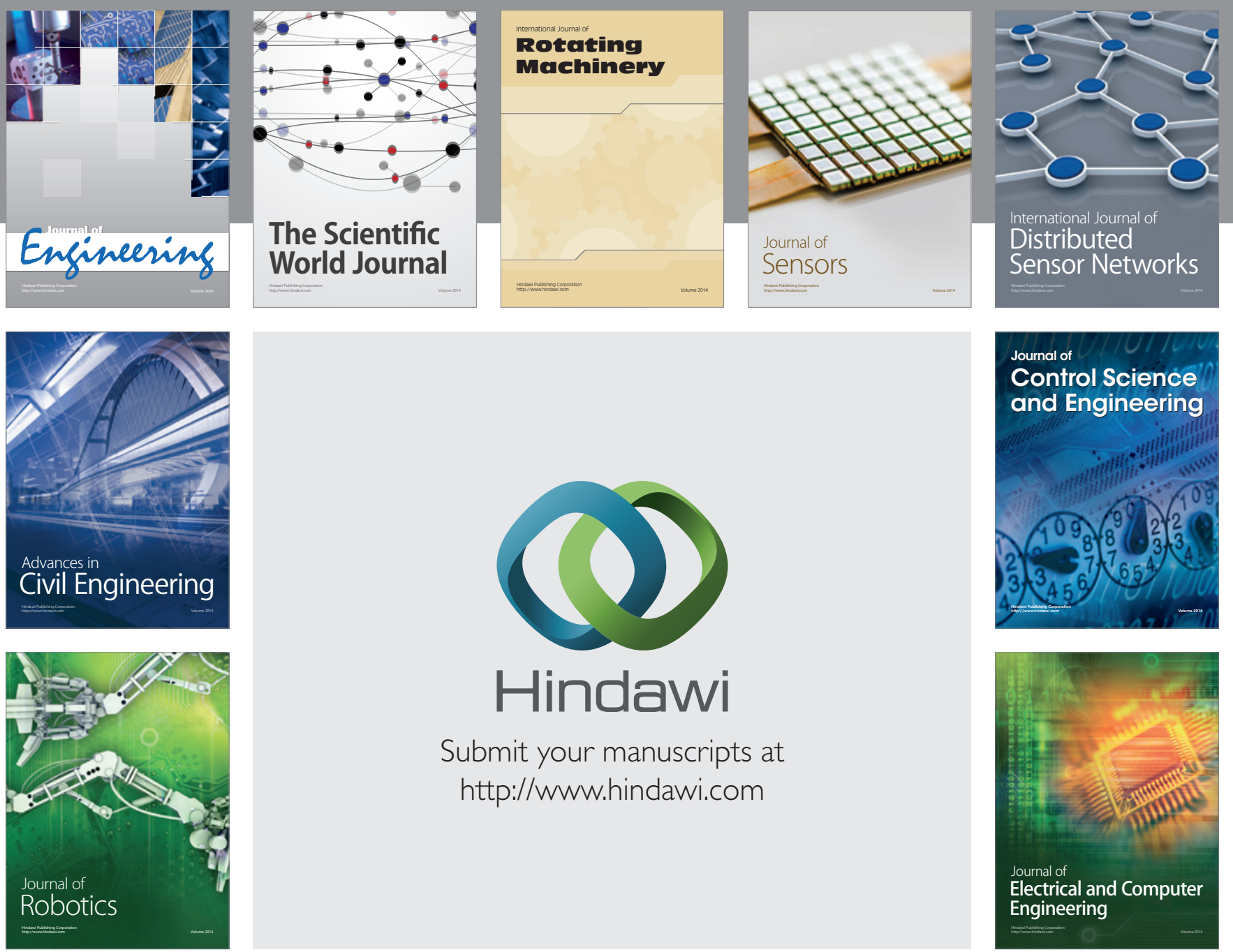

Submit your manuscripts at

http://www.hindawi.com
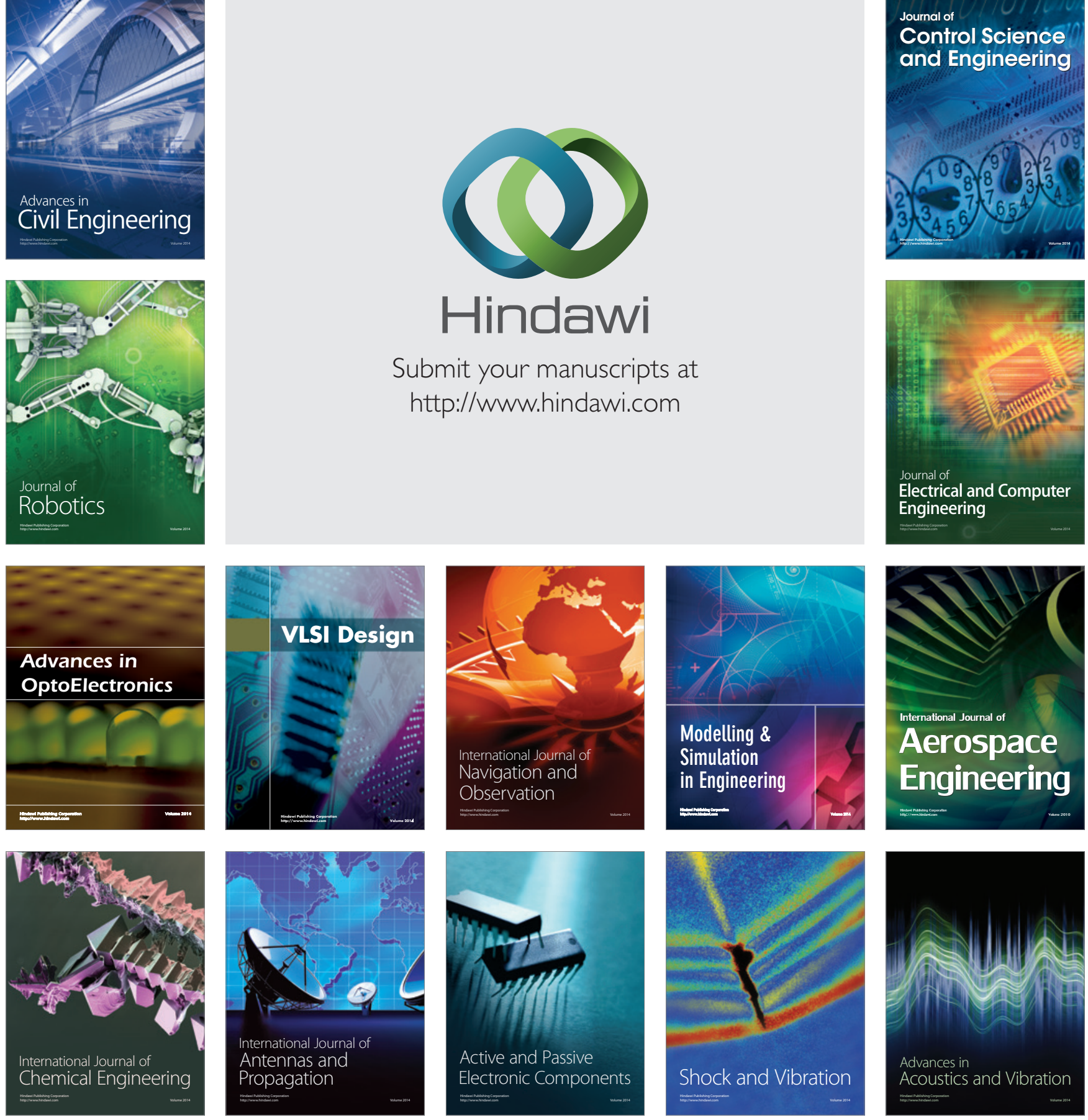